ISSN: 0213-2087 e-ISSN: 2444-7080

DOI: https://doi.org/10.14201/shhcont372019139157

\title{
UN HETERODOXO EN MATERIA SEXUAL: LA DEFENSA DE LA MASTURBACIÓN POR EL ANARQUISTA ESPAÑOL ANTONIO G. LLAURADÓ (1932-1935)
}

\author{
$A$ beterodox in sexual matters: the defense \\ of masturbation by the Spanish anarchist \\ Antonio G. Llauradó (1932-1935)
}

\author{
Alejandro LORA MEDINA \\ Universidad de Sevilla
}

Recibido: 12/07/2018 Revisado: 05/08/2019 Aceptado: 02/09/2019

RESUMEN: Este artículo pretende analizar el pensamiento del militante anarquista Antonio G. Llauradó a partir de los distintos artículos que publicó en la revista Estudios durante los años treinta. A través de ellos se ofrece una visión general de su modo de entender la vida y al ser humano, y, más concretamente, sobre la sexualidad y sus distintas manifestaciones y prácticas. La originalidad de su pensamiento reside en defender desde un punto de vista médico y no ideológico el hábito de la masturbación, frente a otros discursos existentes que condenaban el autoerotismo como foco de enfermedades y afecciones psico-sexuales.

Palabras clave: España; anarquismo; sexualidad; masturbación; Antonio Llauradó.

ABSTRACT: This article aims to analyze the thinking of the anarchist militant Antonio G. Llauradó using the different articles that he published in the magazine Estudios during the 1930s. Through them, we offer a general vision of their way of understanding life and the human being, and, more specifically, sexuality and its different manifestations and practices. The freshness of his thinking lies in defending the habit of masturbation from a medical and not an ideological point of view, as opposed to other existing discourses that condemned autoerotism as a focus of psycho-sexual illnesses and diseases.

Key words: Spain; anarchism; sexuality; masturbation; Antonio Llauradó. 


\section{INTRODUCCIÓN}

El anarquismo español no sólo se caracterizó por la acción directa y su radical visión política, sino que también desarrolló una concepción diversa de aquellos parámetros éticos y morales que eran necesarios para la configuración de un individuo plenamente libre. La transformación del sistema de valores tradicional, influido directamente por el pensamiento católico y la moral burguesa, y su posterior modificación por uno nuevo, eran tan valoradas y necesarias como la subversión del orden establecido. Una sociedad plenamente libertaria no sólo se conseguiría con la destrucción del Estado, sino que habría que implementar una nueva moral, también sexual, que abarcaba la educación, la higiene, el amor libre, el aborto, el control de la natalidad, la eugenesia, etc. El presente trabajo aborda cómo, a pesar de que el anarquismo ondeó la bandera de la libertad sexual, muy influido por los estudios médicos de la época, prácticas sexuales como la masturbación fueron mayoritariamente criticadas y configuradas como "tendencias sexuales anormales». En este contexto, emerge la figura de Antonio G. Llauradó que, en contra de la opinión generalizada, iba a defender los beneficios de dicha práctica. A través de sus distintos escritos en la revista Estudios, el militante libertario establece las pautas de su pensamiento. Todo ello en una etapa crucial de la historia contemporánea de España, como fueron los años treinta del siglo XX, marcada por el proceso de modernización, tanto político como cultural, que experimentó el país en medio además de una profunda conflictividad social.

El escaso tratamiento que ha recibido esta temática por parte de la historiografía para este periodo y movimiento concreto hace difícil la composición de un marco bibliográfico específico. Aunque destacan los trabajos de Richard Cleminson, con su correspondiente análisis de la homosexualidad y la masturbación para el mundo ácrata en el siglo XX, se trata de un tema que, por lo general, y aunque se inserta dentro del ámbito de actuación de la historia cultural, no se le ha prestado la importancia debida. Una aproximación más exhaustiva sí ha recibido el estudio de la sexualidad en general y la masturbación durante los siglos XIX y XX, especialmente en relación a la evolución del pensamiento médico y social sobre su génesis e influencia. En este acercamiento social y cultural a la historia de la sexualidad destacan los trabajos de Francisco Vázquez García, José Benito Seoane Cegarra, Andrés Moreno Mengíbar, y, especialmente, Jean Louis Guereña, cuya contribución al estudio de la sexualidad en época contemporánea ha sido fundamental².

1. La Revista Blanca, ${ }^{\circ} 118,15$ de abril 1928, pp. 695-697.

2. R. Cleminson, Anarquismo y sexualidad en España (1900-1939), Publicaciones de la Universidad de Cádiz, Cádiz, 2008, pp.129-150; R. Cleminson, Anarquismo y homosexualidad. Antología de artículos de la Revista Blanca, Generación Consciente, Estudios e Iniciales (1924-1935), Huerga y Fierro Editores, Madrid, 1995, pp. 53-60; P. BuRKe, ¿Qué es la historia cultural?, Barcelona, Ed. Paidós Ibérica, 2006, p. 15; F. VÁzQuEz 

POR EL ANARQUISTA ESPAÑOL ANTONIO G. LLAURADÓ (1932-1935)

\section{UnA FIGURA DESCONOCIDA: IDEOLOGÍA Y PENSAMIENTO DE ANTONIO G. LLAURAdÓ}

La figura de Antonio Llauradó es como la de tanto militantes ácratas de la época, marcada por el desconocimiento de unas vidas dedicadas enteramente y desde el anonimato a la lucha por la extensión de sus ideas. De Llauradó, posiblemente de familia catalana, apenas se conocen algunos datos sueltos como el hecho de que fue detenido junto a otros anarquistas en septiembre de 1893 por el atentado contra el general Arsenio Martínez Campos ${ }^{3}$. Un año después, a pesar de haber sido ejecutado su autor, seguía detenido; desconociéndose totalmente qué fue de su vida a partir de entonces. Sin embargo, a través de sus numerosos artículos en prensa - en concreto las revistas Estudios e Iniciales entre 1932 y 1935- podemos conocer parte esencial de su pensamiento. Ideas que están marcadas por una serie de principios que considera básicos y que le definen como anarcoindividualista, materialista, defensor de la Eugenesia y abierto partidario de la libertad sexual. Concepciones todas ellas que

García, J. B. Seoane Cegarra, "España y la cruzada médica contra la masturbación (1800-1900). Elementos para una genealogía», Hispania, vol. 64, n²18 (2006), pp. 836-867; F. Vázquez García, A. Moreno Mengíbar, "Genealogía de la educación sexual en España: de la pedagogía ilustrada a la crisis del estado del bienestar", Revista de Educación, n³09 (1996), pp. 67-94; J. L. Guereña, La sexualidad en la España contemporánea (1808-1950), Cádiz, Universidad de Cádiz, 2011; J. L. Guereña, Detrás de la cortina. El sexo en España: 1790-1950, Madrid, Ed. Cátedra, 2018.

3. El intento de asesinato de Martínez Campos, el símbolo militar del nuevo sistema y el líder del pronunciamiento militar que provocó el retorno de los Borbones a España, se inserta en un periodo de represión social y sindical contra el movimiento anarquista que lleva al surgimiento de la "propaganda por el hecho». Sus autores se consideran mártires de una causa superior en nombre de la que entregan su vida como ejemplo máximo de sacrificio con la intención de despertar las conciencias populares y provocar un alzamiento revolucionario de la población. Estos magnicidios se extenderían por todo el globo afectando a países como Francia, Austria, Italia, EEUU y, evidentemente, España. El atentado contra el militar y político español, a pesar de no perder la vida, conllevó la condena a muerte y ejecución de su impulsor, el también anarquista catalán Paulino Pallás. Sin embargo, esta acción lejos de detener dichas acciones contra el Estado, las acabarían fomentando. Un mes después de la muerte de Pallás, otro anarquista, esta vez el aragonés Santiago Salvador arrojaba dos bombas contra el patio de butacas del Teatro del Liceo de Barcelona, matando a 22 personas. Este sería uno de tantos atentados que darían paso a un largo intercambio de acciones violentas entre ambas partes, que llevarían al asesinato del presidente del gobierno y principal estadista del régimen de la Restauración, Antonio Cánovas del Castillo, en agosto de 1897 por el anarquista italiano Michele Angiolillo. Aunque no fue el único homicidio anarquista de un alto cargo (habría que añadir los asesinatos de sendos presidentes del Consejo de Ministros, José Canalejas en 1912 y Eduardo Dato en 1921), sí fue de los más importantes por la personalidad e importancia del político malagueño en la estructura y funcionamiento de la monarquía de Alfonso XIII. J. Álvarez Junco, La ideología política del anarquismo español (1868-1910), Ed. Siglo Veintiuno de España, Madrid, 1991, p. 483; S. SueIro SEOANE, "El terrorismo anarquista en la literatura española", Espacio, tiempo y forma. Serie V, historia contemporánea, 20 (2008), pp. 38, 39; J. Avilés FARré, La daga y la dinamita. Los anarquistas y el nacimiento del terrorismo, Barcelona, Tusquets Editores, 2013, pp. 282, 324, 325; M. ÍÑguEZ ÍñIGUEZ, Esbozo de una enciclopedia del anarquismo español, Madrid, Fundación Anselmo Lorenzo, 2001, p. 333. 
trascienden su campo de acción para significar el principio básico del que parte su concepción del mundo y del ser humano.

Para Antonio G. Llauradó, la anarquía se basa en el individualismo y el respeto a las leyes de la naturaleza, aunque considera fundamentales para el desarrollo interno del menor algunas células colectivas básicas como la familia. Estas leyes naturales, que «se sienten, no se imponen, porque son inalienables ${ }^{4}$, tienen en la teoría de la evolución y el fenómeno de la selección natural uno de los principios fundamentales de la existencia humana 5 , el desarrollo de la conciencia. La necesidad de encontrar respuestas sobre el sentido vital del hombre le lleva a centrarse en la ciencia como herramienta de la razón para profundizar en el conocimiento de la vida y, en concreto, en la biología, a partir de la que defiende la idea del origen eléctrico de la vida y el intelecto. La obsesión anarquista por la incesante demostración del pensamiento científico le lleva a justificar sus aseveraciones en las investigaciones de varios científicos expertos en la materia. Por un lado, la teoría ontogénica de la formación de la célula a partir de reacciones electrolíticas del científico ruso Georges Lakhovsky y la teoría atómica del físico danés Niels Henrik Bohr. A partir de estas novedosas contribuciones que databan de principios de siglo, y que otorgan a su pensamiento un carácter de progresismo y modernidad, Llauradó señala que la capacidad intelectiva del ser humano se nutre de los sentidos a través de los que interpreta el mundo y que, a su vez, nutren su memoria. Eso demostraría que la electricidad es la esencia básica de la vida y del comportamiento físico del hombre, el cerebro y su actividad. Pero en su opinión, la centralidad de lo eléctrico no se trataba de una idea novedosa, sino que ésta ya se encontraba presente en el pensamiento del filósofo presocrático Tales de Mileto hace más de 2.600 años ${ }^{6}$, lo que

4. Estudios, n¹08, agosto de 1932, p. 36.

5. La influencia y relevancia del lamarckismo y el darwinismo en el pensamiento anarquista de los años treinta es evidente en cuanto a su percepción del ser humano como especie y su relación con el medio ambiente como factor determinante en la configuración intelectiva humana. El tópico del hombre primitivo bueno por naturaleza que vive en un mundo libre y sin reglas es superado en beneficio de la idea del progreso constante de la humanidad, negándose abiertamente — como haría Germinal Esgleas en un artículo en La Revista Blanca en 1931- que la anarquía o un régimen similar hubiera podido existir en los pueblos antiguos, ya que indefectiblemente la conciencia evoluciona con el tiempo. La Revista Blanca, nº185, 15-02-1931, p. 439. De este modo, y como si cada autor que había existido hubiera aportado una pieza pequeña pero fundamental al puzzle que es el ser humano y la vida en un sentido mayestático, de Charles Darwin pervive la idea de la selección natural y la vida lucha por la supervivencia, mientras que de Lamarck queda la importancia otorgada al medio en la configuración evolutiva de las especies. Solidaridad Obrera, n¹838, 19-03-1938, p. 1; Iniciales, n4, junio 1929, pp. 108, 109; Cultura y Pedagogía, n¹7, 29-041937, p. 4; La Revista Blanca, n³51, 11-10-1935, pp. 979, 980.

6. En esta misma línea se enmarca también la figura de Juan García Oliver, conocido revolucionario y autor de numerosas acciones contra el Estado, y que tantos años en prisión le permitieron precisamente ampliar ese conocimiento general del mundo y de sus protagonistas: «Leí a los griegos, a Tales de Mileto, a Heráclito de Efeso. Conozco a Antístenes y a Diógenes, a los cínicos. Sé de los estoicos, de Teofastro, de 

POR EL ANARQUISTA ESPAÑOL ANTONIO G. LLAURADÓ (1932-1935)

refleja el gusto ácrata por la historia, la filosofía y, en definitiva, todo libro que pudiera aportar algo al intelecto del hombre rebelde. Y sería precisamente esta confianza en el poder de la materia, aseverado por las teorías de la constitución atómica y la noción de los electrones — respaldadas a su vez por las tesis, no sólo de Bohr, sino también de Dmitri Mendeléyev, Ernest Rutherford y Albert Einstein- lo que confirmarían el materialismo como el sistema filosófico por antonomasia, ya que es el que mejor se adaptaría en su opinión a los continuos adelantos de la ciencia?

Por doquiera surge la electricidad. Todo induce a creer que la electricidad es el alma del Universo. Pero desde sus primeras manifestaciones se nos muestra material: ese alma debe de ser material. Y esa materia en movimiento es energía. La energía es propiedad de manifestación de la materia; es una consecuencia; es después ${ }^{8}$.

Su visión de la vida le conduce a creer en la existencia de un fuerte determinismo biológico que afectaría al ser humano como especie —es lo que denomina ética genésica-, inclinación de la que no se puede escapar, de ahí que sacralice hasta límites insospechados el concepto y exalte la eugenesia como filosofía social que garantizaría el cuidado de la misma en el tiempo. La importancia de la eugenesia en el anarquismo español, basada en su respeto por el conocimiento científico, lo entronca con otras corrientes de pensamiento contemporáneas herederas de un darwinismo social progresista que aceptan la importancia de los factores biológicos como constitutivos de la herencia patológica. La crítica se extiende al Estado y a la sociedad burguesa como culpables últimos de la decadencia de las naciones y un decrecimiento poblacional ligado a un empobrecimiento genético que haría que cada vez nacieran individuos más enfermos. En esta línea, Llauradó, citando el libro «Fisique and Character» (1931) del psiquiatra alemán Ernst Kretschmer, apela a la correlación entre el aspecto físico y la mente con el desarrollo de las enfermedades mentales para señalar a la eugenesia como la única vía posible capaz de encauzar desde la biología dichos factores que afectan al determinismo social. Nuevamente, se apoya en nombres de la talla de Lamarck, Darwin, Mendel, Müller, Pawlow, Freud, Galton y Malthus?.

Marco Aurelio; de Sócrates y sus diálogos recogidos por Platón y de las anécdotas narradas por Jenofonte...». J. García Oliver, El eco de los pasos. El anarcosindicalismo en la calle, en el Comité de Milicias, en el gobierno, en el exilio, Barcelona, Ed. Ruedo Ibérico, 1978, p. 78.

7. Estudios, $\mathrm{n}^{\circ} 108$, agosto de 1932, p. 36; Estudios, n²122, octubre de 1933, pp. 34, 35; Estudios, n ${ }^{\circ} 109$, septiembre de 1932, pp. 7, 8; Estudios, n¹25, enero de 1934, p. 44; Estudios, n 143 , julio de 1935, pp. $22-24$.

8. Estudios, n`143, julio de 1935 , p. 23.

9. Estudios, n¹10, octubre de 1932, p. 33; Estudios, n¹27, marzo de 1934, pp. 32, 33. En esta línea se expresaba también Higinio Noja Ruiz en Estudios ya que se trata de un pensamiento muy extendido en el anarquismo de principios de siglo: «[...] la población no sólo decrece sino que degenera. Cada día la raza pierde vigor y se reduce la duración media de la vida humana. Vivimos rabiando y aunque procuramos limitar el número de nuestras obligaciones y multiplicamos nuestros esfuerzos, no nos es posible salir con 

POR EL ANARQUISTA ESPAÑOL ANTONIO G. LLAURADÓ (1932-1935)

Analizada la especie, Llauradó vuelca su mirada hacia el ser humano para abordar el papel biológico y social que juegan mujeres y hombres como partes constitutivas de la misma especie. En su opinión, se trata de dos entes totalmente distintos, no sólo a nivel físico, sino especialmente a nivel intelectivo-emocional, cayendo así en la asociación del sexo con ciertos tópicos tradicionales de género. Esta realidad, que no es exclusiva del anarquismo sino que es extensiva a toda la sociedad, refleja que la construcción de las identidades de género fue un proceso lento en el que seguía persistiendo con fuerza una visión muy tradicional. La peculiaridad de su pensamiento es que, nuevamente, argumenta y sustenta sus aseveraciones en la ciencia —en este caso, menciona los trabajos del médico alemán Benjamin Lipschütz y del fisiólogo austríaco Eugen Steinach, pionero en el campo de la endocrinología-, señalando que las diferencias psíquicas entre hombres y mujeres son consecuencia de factores biológicos que buscan asegurar la permanencia de la especie humana. En este sentido, para el colaborador de Estudios la naturaleza manda y el ser humano, como parte de su creación, obedece; en el caso de la mujer, la ley natural se manifestaría a través de la maternidad, según la cuál la naturaleza habría dispuesto a ésta tener hijos y al hombre protegerlos. Según esto, aunque consideraba a la fémina "maltratada» por su condición generatriz al girar toda su vida siempre en torno a la reproducción y al cuidado de los niños, para Llauradó la maternidad es desde un punto de vista biológico incompatible con el trabajo. Esta supuesta realidad incontestable marcada por la herencia y la evolución le lleva a desarrollar un pensamiento utilitarista en el que el ser humano no sólo no tiene posibilidad de alterar su misión vital, sino que no existe nada más importante que la continua supervivencia de la raza humana ${ }^{10}:$ :Somos víctimas de la Especie. Morimos

la carretera a lo llano. Somos débiles. Nuestros músculos parecen hechos de masa de merengue y nuestra sangre carece de calor. Nuestra capacidad de resistencia disminuye alarmantemente [...] Nuestra existencia es la débil y efímera palpitación de un fuego fatuo». Estudios, n80, abril de 1930, p. 8. Sobre la importancia de la eugenesia en el pensamiento anarquista, véase R. Cleminson, Anarquismo y sexualidad en España (1900-1939), Cádiz, Servicio de Publicaciones de la Universidad de Cádiz, 2008; R. Álvarez Peláez, "Eugenesia y darwinismo social en el pensamiento anarquista", en El anarquismo español y sus tradiciones culturales, Frankfurt am Main, Vervuert-Iberoamericana, 1995, pp. 29-40; R. Álvarez Peláez, "Félix Martí Ibáñez y la eugenesia en España", en Actas del I Simposium Internacional Félix Martí Ibáñez: Medicina, historia e ideología, Valencia, Servicio de Publicaciones de la Generalitat Valenciana, 2004, pp. 59-76; F. NAVARRO NAVARRo, El paraíso de la razón. La revista 'Estudios' (1928-1937) y el mundo cultural anarquista, Valencia, Ed. Alfons el Magnànim/Servicio de Publicaciones de la Generalitat Valenciana, 1997. Sobre la implementación de dichas teorías fuera del anarquismo, véase M. A. BARrachinA, "Maternidad, feminidad, sexualidad. Algunos aspectos de las primeras jornadas eugénicas española (Madrid, 1928 - Madrid, 1933)", Hispania, 64/218 (2004), pp. 1004-1026.

10. Estudios, n¹10, octubre de 1932, pp. 33, 34; Estudios, n'119, julio de 1933, p. 20. Esta idea se inserta dentro de un debate mucho más amplio en el anarquismo español sobre la función social y vital de la mujer en la vida y que llevaría a exaltar la acción fecundadora de la naturaleza a través del sexo femenino, haciéndose extensiva también a la crianza de los hijos, y a destacar la función de la mujer como compañera, 
para que viva el germen. Por eso tiene tanta importancia el sexo en la vida. Como que somos su instrumento, su juguete, su obra y su víctima» ${ }^{11}$.

Este discurso, no sólo le conduce a centrarse en la sexualidad y en sus distintas manifestaciones como el eje principal de la vida, sino que le permite explorar y desarrollar una visión particular de la misma a partir del concepto del sensualismo. Bajo este término, Llauradó encuadra la sexualidad, el erotismo, la "sexualización» de los cuerpos y el placer sexual como un todo que debe poder experimentarse libremente y que considera uno de los grandes logros de la modernidad: "Es un ansia de liberación y hambre de vida "12. En este sentido, el sexo no puede tener límites ni cortapisas porque se trata de un instinto natural que no puede ni debe ser ocultado, de ahí que sea contrario a la castidad, la abstención sexual y cierto moralismo ácrata de corte naturista que

trabajadora y revolucionaria. Dentro del movimiento libertario iban a surgir posiciones tanto a favor como en contra del pensamiento de Llauradó. Militantes como Leandro Carré (conocido en los medios cenetistas como Fausto Brand) abogaban porque la mujer debía centrarse en la esfera doméstica, no por creer en la inferioridad femenina, sino porque el trabajo ponía en riesgo la salud de la madre. Mientras, anarquistas como Lucía Sánchez Saornil, una de las fundadoras de Mujeres Libres, criticaba este pensamiento de raíz biologicista por convertir a la mujer en una mera fábrica de hijos. El problema de los sexos iba a tener que conciliar las particularidades biológicas de mujeres y hombres con el potencial filosófico de convertirlos en dos mitades diferentes pero complementarias de un mismo ser que necesitaba de su acción conjunta e igualitaria para triunfar en la lucha social. El triunfo de un discurso de género y la construcción de una identidad femenina como vía indispensable para luchar junto al varón por la consecución de la idea revolucionaria se haría realidad durante los años treinta con el surgimiento de colectivos específicamente femeninos que llevarían a la creación durante la Guerra Civil de Mujeres Libres, organización pionera en unir la lucha contra la denominada "triple esclavitud" de la mujer: la ignorancia, el capitalismo y el patriarcado. Sin embargo, esto no fue óbice para la existencia de manifestaciones sexistas dentro del movimiento libertario y que atentaban contra la igualdad integral defendida a nivel teórico por una ideología para la que hombres y mujeres eran iguales en todos los aspectos. R. E. Ríos LLORET, "Obedientes y sumisos: sexualidad femenina en el imaginario masculino de la España de la Restauración", Ayer, 63 (2006), pp. 187-209; N. Aresti Esteban, "Cuestión de dignidad. Género, feminismo y culturas políticas”, en La Restauración y la República: 1874-1936, Madrid, Ed. Marcial Pons, 2015, pp. 85-110; M. G. EsPigado Tocino, "Placer, sexualidad y maternidad», en Cuerpos de mujeres: miradas, representaciones e identidades, Granada, Servicio de Publicaciones de la Universidad de Granada, 2007, pp. 329-334; A. M. Aguado, "Cultura socialista, ciudadanía y feminismo en la España de los años veinte y treinta", Historia Social, 67 (2010), pp. 131-153; D. RAmos PALOmo, "La construcción cultural de la feminidad en España. Desde el fin del siglo XIX a los locos y politizados años veinte y treinta", en Feminidades y masculinidades: arquetipos y prácticas de género, Madrid, Alianza Editorial, 2014, pp. 21-46; M. NASH, Mujer y movimiento obrero en España, 1931-1939, Barcelona, Editorial Fontamara, 1981, pp. 22-28, 45-47, 65-71, 86-94; M. ACKelsberg, Mujeres Libres. El Anarquismo y la lucha por la emancipación de las mujeres, Barcelona, Virus editorial, 1999, pp. 36, 58, 148-164; M. NASH, Rojas. Las mujeres republicanas en la Guerra Civil, Madrid, Taurus Alfaguara, 1999, 2007, pp. 35-48, 133-142; A. LORA MEDiNA, «La visión ontológica de la mujer y el hombre en el anarquismo español de los años treinta: identidad y género a debate», Brocar, 41 (2017), pp. 181-203.

11. Estudios, $\mathrm{n}^{\circ} 112$, diciembre de 1932, p. 34.

12. Estudios, n¹19, julio de 1933, p. 19. 
atacaba la erotización de los cuerpos desnudos y la práctica del sexo como única vía para tener descendencia. En su afán por justificar sus aseveraciones racionalmente iba a recurrir a una pléyade de médicos y científicos de la época, algunos de reconocido prestigio internacional, para sentenciar que todo gira en torno al sexo, la «más noble función fisiológica»" ${ }^{13}$. De este modo, para justificar la estrecha relación e importancia del sexo y la psique desde un punto de vista fisiológico, así como el vínculo especial de la vida sexual con la eugenesia, el amor romántico y el aspecto económico de la humanidad cita a los psiquiatras Ernst Kretschmer y Sigmund Freud, los médicos Nicola Pende, Roberto Nóvoa Santos, Antonio Austregesilo y Gregorio Marañón, además de A. W. Nemilow y Thomas Malthus. La intención de Llauradó es remover las conciencias, revolucionar las mentes, demostrar que el sexo es biología y que lo biológico no es ni puede ser considerada algo vicioso ni vergonzoso, ya que el individuo no controla su instinto sexual, sino que es éste el que controla al hombre ya que es la forma que tiene la naturaleza de manifestarse como creación y vida en el ser humano ${ }^{14}$ :

La redención no debe ser sólo económica, ni la libertad sólo de conciencia. Son necesarias también la redención y libertad sexuales; que tienen tanta importancia, por lo menos, como las demás [...] Mientras no echéis por la borda el lastre de la moral sexual no podéis llamaros revolucionarios ${ }^{15}$.

La persistencia de comportamientos tradicionales quedaba de manifiesto en la actitud que muchos libertarios tenían respecto al amor y al sexo, ya que en la práctica sus pautas de conducta respondían más al discurso religioso de la inmoralidad de determinados comportamientos en materia genésica y el miedo al escarnio público por una liberalización de la conducta erótica. Por esta razón, dicha revolución debía

13. Estudios, n 134 , octubre de 1934, p. 16

14. Estudios, nº119, julio de 1933, pp. 19, 20; Estudios, n¹34, octubre de 1934, pp. 15-17; Iniciales, n6, junio de 1935, pp. 9-12. Para el anarquismo español, aunque la configuración de una moral sexual era una reivindicación que se remontaba a comienzos del siglo XX, sería en la década de 1930 cuando ésta adquiera una relevancia significativa dado el aumento sustancial de publicaciones, actos de propaganda y actividades culturales del movimiento libertario, consecuencia directa de la instauración de un sistema democrático en el país. La condena del matrimonio y la prostitución tiene su correlato en la extensión de una visión del cuerpo a partir de postulados naturistas que contemplan el desnudo, no desde una concepción lujuriosa o pornográfica, sino como la manifestación de la belleza natural. La ética sexual anarquista iba a estar profundamente mediatizada por la medicalización de sus postulados, llegando las tesis médicas de la época a convertirse en el elemento central de su concepción de la sexualidad, la higiene, la lucha antivenérea o el control de la natalidad. Estudios, n¹34, octubre 1934, p. 13; H. ANDrés GrANEL, "Anarquismo y sexualidad", Germinal, 5 (2008), p. 68; M. NASH, "La reforma sexual en el anarquismo español», en El Anarquismo español $y$ sus tradiciones culturales, Frankfurt am Main, Vervuert-Iberoamericana, 1995, pp. 286, 287; F. J. NAVARRO NAVARRO, "Sexualidad, reproducción y cultura obrera revolucionaria en España: la revista Orto (1932-1934)", Arbor, 769 (2014), p. 6; R. Cleminson, Anarquismo y bomosexualidad. Antología de artículos de la Revista Blanca, Generación Consciente, Estudios e Iniciales (1924-1935), Madrid, Huerga y Fierro editores, 1995 , p. 35.

15. Estudios, n¹34, octubre de 1934, p. 17. 

POR EL ANARQUISTA ESPAÑOL ANTONIO G. LLAURADÓ (1932-1935)

ir ligada a una labor de educación sexual desde la infancia, a la apología del amor libre y a una labor de lucha permanente contra la moral tradicional, con la crítica del matrimonio y la condena de la prostitución como elementos destacados. Para Llauradó hombres y mujeres eran por igual parte esencial de la familia monogámica libertaria, indispensable para la formación ética y moral de su prole ya que, de lo contrario, sería atentar contra el carácter biológico de las leyes de la naturaleza. En su opinión, mientras el matrimonio era parte constituyente de la sociedad burguesa y de la moral establecida con todos sus formulismos y legalidades, la monogamia — que representaba el fundamento básico del instinto sexual de los animales y, por tanto, también del hombre - solo podía ser garantizada por el anarquismo a través del amor libre, al ser considerado como la filosofía más próxima a los postulados de la naturaleza. La defensa de esta opción amorosa iba a estar inexorablemente unida a la exigencia del derecho de la mujer a ser plenamente autónoma sobre su cuerpo y sus sentimientos. En esta línea progresista y evolucionista de la vida, el amor libre es entendido como el final de un proceso en el que se observa el progreso constante de la humanidad en materia amorosa ${ }^{16}$.

\section{LA SEXUALIDAD Y LAS «DISIDENCIAS SEXUALES» EN EL ANARQUISMO ESPAÑOL}

El anarquismo, aunque se trata de una ideología político-social que persigue la sustitución del orden establecido por un sistema tradicionalmente inclinado al comunismo libertario, es una filosofía que aboga por la configuración de una moral integral que abarque la totalidad de lo humano. Desde esta perspectiva todos los elementos que dan forma a una persona son importantes porque afectan al porvenir de la nueva sociedad y no deben ser dejados al azar. Y entre estos la sexualidad y, en concreto,

16. Estudios, n¹08, agosto de 1932, pp. 35, 36; Estudios, n¹10, octubre de 1932, p. 33. La apuesta por una educación sexual en la infancia no es exclusiva del anarquismo, sino que se encuentra presente en el mundo médico de la reforma sexual española, inspirado en el auge de la pedagogía infantil como ciencia dedicada al estudio y divulgación de que el menor posee sexualidad propia a pesar de no haberse desarrollado totalmente en su plena madurez genital. El desarrollo de una sexualidad correcta que evitara la contracción de enfermedades era condición sine qua non para tener una vida amorosa sin ataduras externas y libre de la presión social de la moral tradicional. El estudio de las relaciones sentimentales, configuradas bajo el término genérico de «amor libre», viene a sancionar en la práctica según la realidad del anarquismo español de principios del siglo XX en España una relación monógama heterosexual que ensalza la libertad individual por encima del respeto a las instituciones vigentes. L. M. LÁzARo LoreNTE, «El debate acerca de la educación sexual en la España de los años treinta", en El currículum: historia de una mediación social y cultural / IX Coloquio de Historia de la Educación, Granada, Servicio de Publicaciones de la Universidad de Granada, 1996, pp. 109-119; M. DEl Cura, R. Huertas García-Alejo, "Medicina y sexualidad infantil en la España de los años treinta. La aportación del psicoanálisis a la pedagogía sexual», Hispania, 64/218 (2004), pp. 987-1002; Solidaridad Obrera, n¹05, 07-01-1933, p. 4; Estudios, nº77, enero de 1930, p. 25; Estudios, n¹28, abril de 1934, p. 32; Acracia, n³07, 19-07-1937, p. 12; La Revista Blanca, n²29, 01-12-1932, p. 408. 

POR EL ANARQUISTA ESPAÑOL ANTONIO G. LLAURADÓ (1932-1935)

las "disidencias sexuales» ocupan una parte importante de la ética sexual que va a ser objeto de apología por parte de la elite cultural ácrata en la década de los años treinta. No será casual que, en cuestiones relacionadas con la medicina y la sexualidad, los principales propagandistas y articulistas libertarios de los años treinta pertenecieran directa o indirectamente al campo médico. Entre estos iban a destacar especialmente Pedro Vallina, Javier Serrano, Roberto Remartínez, Isaac Puente, Alfredo Royo Lloris, Amparo Poch y Gascón, Félix Martí Ibáñez o los hermanos Alcrudo Solórzano. Todos abordaban el tratamiento de los distintos aspectos relacionados con este tema desde una perspectiva higienista que no era privativa de los anarquistas, sino que estaba extendida por los ambientes médicos europeos más progresistas desde finales del siglo XIX. Este acercamiento ácrata a los estudios científico-médicos de la época va a realizarse más como una continuidad de los mismos que como una excepción, coincidiendo con la difusión en España desde los años veinte de los trabajos de destacados divulgadores europeos como Richard von Kraft-Ebing, Henry Havelock Ellis, Sigmund Freud o Gregorio Marañón ${ }^{17}$.

Sería especialmente durante la década de 1930 cuando esta ética sexual iba a encontrar en la Segunda República el marco perfecto para desarrollarla a través de actos de propaganda de todo tipo como artículos en prensa, libros, conferencias, debates en los ateneos, excursiones a la naturaleza, etc. Los avances médicos de finales del XIX y principios del siglo XX — como el desarrollo de las llamadas perversiones sexuales, la "inversión sexual»18 (actual homosexualidad), el autoerotismo o el narcisismocondujeron a la medicalización de los postulados ácratas en esta materia. El discurso sexual no sólo iba a dejarse influir por las tesis médicas, sino que éstas se convierten en el elemento central que iba a dominar su concepción de la sexualidad junto a la defensa de las leyes naturales como fuente de verdad incontestable y, en concreto, la reproducción de la especie. Su importancia era tal que Higinio Noja, maestro racionalista onubense y director de cabeceras como Estudios, Semáforo o UGT-CNT, la define como «el grito de la especie que impone su voluntad de no extinguirse, de perpetuarse en el espacio y en el tiempo» ${ }^{19}$. Para muchos propagandistas, como Augusto Moisés Alcrudo Solórzano, la procreación era la razón del instinto sexual y el ser humano no dejaba de ser un animal en ese sentido biológico. Se trata de una moral para la que sexualidad y la procreación son partes concomitantes inseparables, lo que conduce a

17. M. Ackelsberg, Mujeres Libres. El Anarquismo y la lucha por la emancipación de las mujeres, p. 59; R. Álvarez PeláEz, "Publicaciones sobre sexualidad en la España del primer tercio del siglo XX entre la medicina y la pornografía”, Hispania, 64/218 (2004), p. 953; F. Fernández De Mendiola, Isaac Puente: el médico anarquista, Tafalla, Editorial Txalaparta, 2007, pp. 119, 120.

18. Término acuñado por el sexólogo británico Havellock Ellis en su obra Studies in the Psychology of sex de 1896; obra que, sin embargo, no sería traducida al español hasta 1913.

19. Estudios, no77, enero de 1930, p. 25. 
la exaltación de la biología como pautas que rigen el comportamiento genésico y lleva a la necesaria distinción entre un instinto sexual "normal» y otro desviado ${ }^{20}$.

Es un discurso, sin embargo, que a pesar de su manifiesta hostilidad contra la moral religiosa tradicional comparte con ésta ciertos elementos que no dejan de ser costumbres sociales heredadas de generación en generación. De este modo, los estudios que abogan por una "antinaturalidad" de la homosexualidad o el carácter perjudicial para la salud de la masturbación se anteponen a la defensa de la libertad y el respeto a la libre decisión. Fuera del mundo de la medicina y de los propagandistas, las disidencias sexuales estaban socialmente más próximas a una visión ligada a comportamientos viciosos que a una interpretación médica circunscrita principalmente a la elite cultural ácrata. Su escaso tratamiento y ocultación, así como la casi inexistencia pública de militantes homosexuales conocidos — con la excepción de Lucía Sánchez Saornil—, demuestra que se trata de temas tabú que seguían permaneciendo ocultos. Este silencio era debido, no sólo al recelo que despertaban unas prácticas advertidas como afecciones contra natura y condenadas por la sociedad, sino también por la existencia dentro del movimiento libertario de una corriente de pensamiento progresista que no aceptaba ni la homosexualidad ni la masturbación como formas naturales de vivir la sexualidad propia.

\section{LA MASTURBACIÓN, UN TEMA CONTROVERTIDO. \\ LA DEFENSA DE SU PRÁCTICA POR ANTONIO LLAURADÓ}

A diferencia del escaso tratamiento que recibió la homosexualidad en los medios libertarios, la masturbación fue el tema más abordado dentro de las denominadas disidencias sexuales, tanto por sus implicaciones morales como físicas para la salud. Ya

20. Estudios, n 134 , octubre de 1934, p. 13; Acracia, n³07, 19-07-1937, p. 12; Estudios, n¹13, enero de 1933, p. 53; H. ANDRÉs GRANEL, "Anarquismo y sexualidad», p. 68. A diferencia de otras cuestiones como los anticonceptivos o el aborto, la homosexualidad no fue un tema muy recurrente en los medios libertarios. Los debates fluctuaban entre su comprensión y respeto, con la condena de unas prácticas que eran tildadas por muchos como antinaturales y perjudiciales. El principal propagandista libertario que abordaría el tema fue Félix Martí Ibáñez, que durante la Guerra Civil llegó a ser director de la Consejería de Sanidad y Asistencia Social de Cataluña desde la que impulsaría entre otras medidas la legalización del aborto. En su opinión, se trata de una práctica sexual anormal consecuencia de la alteración del instinto biológico natural y, aunque enfermedad, consideraba que sus practicantes no debían ser perseguidos ni juzgados. A. LorA Medina, "Una aproximación a la homosexualidad según Félix Martí Ibáñez: médico libertario español», en Normes et déviances dans le monde luso-hispanophone, Nancy, PUN-Éditions Universitaires de Lorraine, 2013, pp. 159-177; F. VÁzQuez García, "El discurso médico y la invención del homosexual (ESPAÑA 1840-1916)", Asclepio, 53/2 (2001), p. 158; R. Cleminson, Anarquismo y bomosexualidad..., pp. 19, 148, 149; F. VÁzQuez García, R. Cleminson, Los invisibles: una bistoria de la bomosexualidad masculina en España, 1850-1939, Granada, Ed. Comares, 2001, p. 151; X. Díez, «Amaos y no os multipliquéis». El discurso ético-sexual del anarquismo individualista en Cataluña (1927-1937)», Spagna Contemporánea, 21 (2002), p. 115; F. VÁzQuEZ GARcía, "El discurso médico y la invención del homosexual...», p. 158. 
desde finales del siglo XIX, incluso desde el propio mundo médico, se la empezaba a considerar síntoma o causa de enfermedades tanto físicas como psíquicas, al tiempo que no desaparecía la visión peyorativa sobre ella al ser tildada de práctica viciosa. Dicha visión y la influencia del pensamiento religioso estaba ligada a una concepción peyorativa de las mismas y conceptuada como pecado bajo el término de onanismo. Sus practicantes eran tachados de viciosos, inmorales y degenerados, fruto de la insatisfacción de una sexualidad normal y procreadora en pareja. Esta idea de desviación del instinto sexual "natural» iba a ser en parte asumida directa e indirectamente por muchas publicaciones libertarias que seguirían valorando su praxis como síntoma de enfermedad o locura. Aunque su práctica era estimada peligrosa a cualquier edad, la focalización sobre la juventud se debía a que se trataba de un periodo vital en la formación y fijación de la conducta sexual futura del individuo. La definición de la masturbación como causa probable de enfermedad física y/o mental se remontaba al siglo XVIII. Las publicaciones de Onania (1715) y El Onanismo (1760) revitalizaron su concepción como praxis sexual degenerante y origen de enfermedades hasta confluir en los planteamientos médicos de principios del siglo XX. En la cosificación como patología de la masturbación iba a tener un enorme peso la influencia de profesionales médicos como Sigmund Freud, uno de los principales defensores de que dicha práctica podía ser causa de trastornos neuróticos como la neurastenia o afectar a la disminución de la potencia sexual del adulta ${ }^{21}$.

Esta concepción iba a influenciar al mundo de la medicina española de principios de siglo, mezclándose los adelantos médicos con la tradición para conceptuarla como una práctica que perturbaba completamente el desarrollo sexual normal y atentaba contra la moral vigente. En el caso de España, la medicalización de la sexualidad vendría a romper el tradicional control de la Iglesia sobre la moral colectiva en un país marcado por unas estructuras económicas desfasadas, una estructura política en proceso de modernización y una esfera social profundamente inestable, especialmente durante las décadas de 1920 y 1930. En este sentido, médicos como Hermenegildo Puig y Sais, que fuera presidente de la Academia de Ciencias Médicas de Cataluña y del Sindicato de Médicos, en un libro publicado en 1915 (El Problema de la natalitat a Catalunya: un gravissim perill per la nostra patria) señalaba que la práctica del onanismo era una de las causas del descenso de nacimientos en España. Más radical era el discurso de José de Letamendi — catedrático de Anatomía por la Universidad de Barcelona y de Patología General por la Universidad Central de Madrid, así como miembro de la Real Academia Nacional de Medicina a finales del siglo XIX - para el que tan grave era su praxis que

21. Estudios, n92, abril de 1931, p. 17; R. Cleminson, Anarquismo y sexualidad..., pp. 134-139; E. Gil Perdiguero, A. GonzÁlez de PABlo, «Los valores morales de la higiene. El concepto de onanismo como enfermedad según Tissot y su tardía penetración en España», Dynamis, 10 (1990), pp. 133-141; S. FrEud, Obras completas. Vol. 1., Madrid, Ed. Biblioteca Nueva, 1983, pp. 194-197, 281, 325. 

POR EL ANARQUISTA ESPAÑOL ANTONIO G. LLAURADÓ (1932-1935)

la consideraba peor que la prostitución, a pesar del riesgo a la contracción de enfermedades venéreas. Durante estos años esta "problematización" acerca del tratamiento de la masturbación en relación a otras patologías sanitarias, iba a caracterizarse por su tratamiento en la infancia y el intento de separar el vicio de la práctica fisiológica ${ }^{22}$.

La llegada de los años treinta, no sólo conllevó cambios en el organigrama político y social del país, sino que se produjo un aumento exponencial de las publicaciones. En este auge literario, del que no fue ajeno el movimiento libertario, se publicaron libros y revistas de clara temática sexual por parte de médicos y reformadores sexuales que proyectaban socialmente la necesidad de que se produjeran cambios cualitativos en el seno de la sociedad española. Entre los reformadores ajenos al mundo ácrata, destacarían especialmente el jurista Luis Jiménez de Asúa o los médicos Gregorio Marañón, Gonzalo Rodríguez Lafora, Justo María Escalante, José Sanchis Banús y César Juarros, entre otros. Desde paradigmas médicos y vaciando de tabúes su aproximación a estas prácticas, los reformadores incidían especialmente en la necesidad de educar en sexualidad y no dejar a la ignorancia o la tradición la vía para el desarrollo de prácticas sexuales que resultaran degenerantes del cuerpo y arruinaran la salud. Se pretende eliminar todo rastro de represión en el discurso, especialmente desde la extensión durante los años 20 del psicoanálisis y la comprensión de que determinadas restricciones podían acabar siendo mal interiorizadas por el individuo y acabar desarrollando enfermedades como neurosis u otros trastornos. Además, la masturbación no se libraría tampoco, por parte de estos reformadores como César Juarros, de ser señalada junto al sadismo, uranismo o masoquismo, como perversiones sexuales. Incluso, otro problema que desde la medicina se relacionaba con esta práctica sería su estrecha relación con la inversión sexual, la homosexualidad, de la que según autores de la época podría ser causante ${ }^{23}$. El anarquismo iba a mantener una visión decimonónica de crítica y condena de la práctica masturbatoria debido a la tardía recepción en España de la campaña médica

22. R. Cleminson, Anarquismo y sexualidad..., pp. 138, 139, 141, 150; F. VÁzQuez García, A. Moreno MengíbAR, Sexo y razón. Una genealogía de la moral sexual en España (siglos XVI-XX), Madrid, Akal, 1997, p. 259; R. Álvarez PeláEz, "Publicaciones sobre sexualidad en la España del primer tercio del siglo XX: entre la medicina y la pornografía", Hispania, vol. 64, n²18 (2004), p. 949; F. VÁzquez García, J. B. Seoane Cegarra, "España y la cruzada médica contra la masturbación (1800-1900). Elementos para una genealogía", Hispania, 64/218 (2004), pp. 841-845; E. Rodríguez Ocaña, Por la salud de las naciones. Higiene, microbiología y medicina social, Madrid, Akal, 1992, pp. 8-26.

23. R. Álvarez Peláez, "Publicaciones sobre sexualidad en la España del primer tercio del siglo XX: entre la medicina y la pornografía”, Hispania, vol. 64, n²18 (2004), pp. 948, 949; F. VÁzQuez García, A. Moreno Mengíbar, Sexo y razón. Una genealogía de la moral sexual en España (siglos XVI-XX), Madrid Akal, 1997, p.135-141; F. VÁzQuez GARCíA, «El discurso médico y la invención del homosexual (España, 1840-1916), Asclepio, vol. 53, fasc. 2 (2001), p. 153; F. VÁzQuez García, R. Cleminson, Los invisibles: una historia de la bomosexualidad masculina en España (1850-1939), Granada, Ed. Comares, 2011, pp. 113-116, 146-160; J. UGarte Pérez, "La matriz del deseo: del género a lo genital», Ayer, no87 (2012), p. 36. 

POR EL ANARQUISTA ESPAÑOL ANTONIO G. LLAURADÓ (1932-1935)

antionanista en relación a otros países del entorno occidental europeo. Bajo una mirada terapéutica, los «vicios solitarios», eran codificados como una costumbre perjudicial para la salud, tanto o más que el alcoholismo o el tabaquismo. La Revista Blanca —uno de los voceros principales del anarquismo español de los años treinta y propiedad de la familia Montseny-Mañé-, en su Consultorio General, señalaba que la práctica del onanismo conducía irreversiblemente al padecimiento de graves enfermedades sexuales y a la impotencia, además de influir severamente al desarrollo de la inteligencia. Aunque su práctica era estimada peligrosa a cualquier edad, la focalización del problema iba a recaer sobre la juventud, dado que se trataba de un periodo vital en la formación y fijación de la futura conducta sexual del individuo. Por esta razón, la mayoría de las consultas a la revista procedían de adolescentes varones, principalmente entre 18 y 20 años, que relataban sus problemas físicos consecuencia del abuso de dicha práctica o pidiendo consejos sobre cómo evitarla. Las respuestas, que generalmente corrían a cargo del Dr. Klug — seudónimo del médico anarquista barcelonés Javier Serranoiban desde tomar baños fríos o templados y regímenes alimenticios reconstituyentes, hasta la recomendación de la unión sexual. Esta idea estaba ligada a la noción de que un abuso de la masturbación provocaba de forma irremediable una pérdida energética del llamado «instinto de propagación». Esta concepción del gasto sexual, influido por la literatura higienista del siglo XIX, se traduce en un discurso antirreligioso acusándose a la moral católica a empujar a los jóvenes a caer en estas prácticas ante la imposibilidad de satisfacer de forma natural sus impulsos orgánicos básicos (sin tener que recurrir al matrimonio o a la prostitución) ${ }^{24}$.

Sin embargo, dado el carácter antidogmático de la ideología anarquista no iba a generarse un discurso unívoco acerca de la masturbación, aunque sí bastante uniforme en líneas generales salvo una excepción. Su apoyo o condena iba a basarse en argumentos exógenos al anarquismo, fundamentados principalmente en los descubrimientos científicos y el pensamiento médico de la época. Para Isaac Puente, una de las personalidades intelectuales más conocidas en el anarcosindicalismo de los años treinta, se trataba de una práctica que era consecuencia directa de la moral religiosa tradicional y la ausencia de una pedagogía sexual que permitiera al individuo vivir libremente su sexualidad. Entre sus secuelas estaba el sentimiento de culpa que se extendía entre la juventud por la extensión de la cultura de la represión, la ocultación y la ignorancia en todo lo relativo al sexo. El médico vasco proponía incluirla como enfermedad infantil para alejarla de la consideración peyorativa que tenía, recetando como única solución viable una educación sexual integral ya que descartaba que ésta fuera la causante de dolencias físicas graves, salvo un debilitamiento general del cuerpo que le impediría hacer frente a enfermedades más graves. En esta línea, otros, como el anarcoindividualista

24. La Revista Blanca, n²97, 28-09-1934, p. 738; La Revista Blanca, n³16, 08-02-1935, p. 140; La Revista Blanca, n³29, 10-05-1035, pp. 453, 454; La Revista Blanca, n³40, 26-07-1935, p. 718. 
Mariano Gallardo, la conceptúan abiertamente como sinónimo de vicio y delito sexual al nivel de la prostitución, el libertinaje, el adulterio o las violaciones, siendo el único recurso viable la extensión del amor libre. En su opinión, la ausencia de una canalización normal y biológica del apetito sexual empujaba a los jóvenes a praxis lesivas para su propia salud, prácticas en las que el propio autor confesaba haber incurrido en su adolescencia; al hacerlo pretendía demostrar que no debe existir miedo o vergüenza en admitirlo, sino admiración porque se trataba de un hábito superable con esfuerzo y comprensión ${ }^{25}$.

Más en línea con una visión patológica de la masturbación, el médico naturista Roberto Remartínez la consideraba una enfermedad en sí cuya peligrosidad radicaba en la excitación que producía en el sistema nervioso y que, junto a la ausencia de una correcta higiene y un abuso prolongado, era la causante de graves enfermedades psicosexuales como la impotencia, la espermatorrea, la eyaculación precoz, la incapacidad sexual y la neurosis. Tal llegaría a ser el volumen de consultas recibidas en la sección «Preguntas y respuestas» de la revista Estudios que Remartínez, encargado de responderlas, iba a publicar en agosto de 1933 una "Respuesta colectiva sobre masturbación". En ella, asumiendo el término bíblico onanismo, suscribía totalmente el pensamiento de José de Letamendi de finales del siglo XIX, considerándolo un vicio pernicioso para la salud y sobre el que no cabía el término medio, debiendo evitarse totalmente su práctica. Incluso llegaba a señalar que, dado los gravísimos problemas que su práctica

25. Anarquistas de otras nacionalidades también incidían en este carácter perjudicial de la masturbación: André Lorulot la consideraba una degeneración fruto de la insatisfacción sexual normal, mientras Camillo Berneri —el único autor que distingue entre prácticas onanistas (niños) y tribadistas (niñas) — señalaba que las escuelas separadas por sexo eran el origen de la extensión de estas prácticas entre la juventud. Estudios, n'92, abril de 1931, p. 17; Estudios, n98, octubre de 1931, pp. 6, 7; Estudios, n'110, octubre de 1932, p. 17; Vía Libre, n57, 20-11-1937, p. 7; El Sembrador, n53, 19-12-1931, p. 1; M. GALLARDo, El sexo, la prostitución, el amor, Toulouse, Ediciones Universo, s.d., pp. 21, 33; F. VÁzquez García, J. B. Seoane Cegarra, "España y la cruzada médica contra la masturbación...”, pp. 837, 838; R. Cleminson, Anarquismo y sexualidad..., pp. 139, 142, 145; R. Cleminson, Anarquismo y bomosexualidad..., pp. 57-68. En línea con el pensamiento de Puente, algunos órganos de prensa asociados a las columnas anarquistas durante la Guerra Civil, ante la necesidad de mantener la salud de sus milicianos, se iban a publicar consejos para resguardar la higiene sexual y que se abstuvieran de prácticas que eran catalogadas de viciosas. La necesidad de alertar sobre estos riesgos llevó a la celebración de conferencias sobre temas relacionados con la sexualidad, como el celebrado en octubre de 1937 en el que un orador de las Juventudes Libertarias de Igualada alertaba de los peligros a los que se exponían los jóvenes que practicaban la masturbación. Cabeceras como 25 División, Antorcha o El Frente señalaban en distintos artículos que la excitación producida por su práctica habitual afectaba directamente al cerebro, debilitando el pensamiento y la fortaleza física del soldado, haciendo que se debilitara y afectara a su herencia: "Conserva tu entereza mental conservando tu vitalidad física no mansturbándote (sic). Piensa que tú no tienes derecho a engendrar hijos tuberculosos y raquíticos y hacer mujeres desgraciadas [...]». El Frente, nº102, 11-10-1937, p. 2; Butlleti C.N.T.-F.A.I., n44, 30-10-1937. 
conllevaba, era mucho más preferible como solución provisional darse a la prostitución, a pesar de considerarla innoble e inmoral, que a los vicios solitarios ${ }^{26}$.

En contra de la opinión general, sin embargo, y siempre a modo de excepción dentro de la corriente dominante en el movimiento libertario español de los años treinta, iba a surgir una visión diferente del problema. Antonio Llauradó, a través de la ecléctica revista Estudios, iba a divulgar un único artículo abordando el tema de la masturbación que llevaría por nombre "Rehabilitación del onanismo». Como su propio nombre indicaba, su objetivo era compendiar opiniones y argumentos científicos que avalaran la defensa de dicha práctica como una opción más para desarrollar una vivencia abierta de la sexualidad. Ese gran logro de la modernidad que era la experimentación libre del placer sexual no podía mantenerse dentro de una concepción que mantenía un carácter abiertamente peyorativo y contrario a una supuesta y correcta higiene personal. Al tratarse de un tema tan controvertido y sabiendo que la fortaleza de su discurso reside en el rigor científico-médico, Llauradó, más que interpretar el pensamiento de los expertos en la materia, se remite a la literalidad de sus escritos para no ser acusado de subjetivismo: "Así, pues, corto y pego de la "Patología» de Nóvoa Santos, libro de texto en casi todas las Facultades de Medicina de España y muchas del extranjero.... ${ }^{27}$. En este sentido, lo que persigue Llauradó no es al experto en medicina con antigua afiliación anarquista y de pensamiento eugénico, sino al médico humanista que se aproxima al hombre, no como paciente, sino como persona para comprender la vida desde una perspectiva antropológica. De este modo, y siempre desde la medicina, en palabras del catedrático gallego, iba a defender que un uso moderado de la masturbación era benigno para el organismo ya que se trataba de satisfacer tendencias fisiológicas naturales e incontrolables ${ }^{28}$ :

La masturbación ni es «vicio, ni enfermedad», ni acto vergonzoso, ni nada: es el «acto indiferente» que, practicado con oportunidad y prudencia, sólo bien puede producir. Él es limpio, higiénico, intrascendente, económico, sin complicaciones ni peligros y moral, perfectamente moral, muchísimo más moral que comprar la colaboración en el burdel, en la mentira o en el matrimonio a fuerza de pesetas, de peligros, decepciones y claudicaciones. ¡Dichoso el día que nadie se vea impulsado a masturbarse! ${ }^{29}$

26. Estudios, nº6, agosto de 1931, p. 27; Estudios, n 99 , noviembre de 1931, p. 26; Estudios, n²0, agosto de 1933, p. 37; Estudios, n¹06, junio de 1932, p. 13.

27. Estudios, n'148, diciembre de 1935, pp. 20-22.

28. La obra del médico gallego Roberto Nóvoa Santos, Manual de Patología General, aunque publicada en España durante el periodo de la Primera Guerra Mundial, alcanzaría cierta notoriedad llegando a las seis ediciones y siendo reeditada en 1934, un año después de la muerte de su autor. J. J. FERnÁNDEZ TEIJEIRO, "Roberto Nóvoa Santos, 75 años después, 1885-1993", Anales de la Real Academia Nacional de Medicina, 2 (2008), p. 358; M. A. Barrachina, "Maternidad, feminidad, sexualidad...", pp. 1011-1013.

29. Estudios, $\mathrm{n}^{\circ} 148$, diciembre de 1935, p. 22. 
La crítica de la masturbación se realiza, no a la práctica en sí, sino al uso excesivo que de ella harían individuos mentalmente inestables o que ya padecían alguna enfermedad psicológica, reafirmando estas aseveraciones en los trabajos de los psiquiatras alemanes Emil Kraepelin y Hermann Emminghaus. La masturbación excesiva causaría en opinión de Nóvoa Santos, y únicamente en aquellos individuos predispuestos, fuertes cefaleas, ataques epilépticos, neurosis y psicosis. De este modo, Llauradó pretendía, citando textos literales del «Manual de Patología General», generar el convencimiento de que el autoerotismo era para la medicina una manifestación más de la sexualidad humana y que no había visos de vicio o degeneración en ello ${ }^{30}$. La visión apologética de esta práctica se sustentaba además en un estudio científico de Raimundo Hamet publicado en 1925 por El Progreso Médico y en el que se negaban las consecuencias funestas que tradicionalmente, y desde otros sectores médicos, se achacaban a la masturbación, incluso entre los menores. Se señalaba que otras prácticas, como el coitus interruptus, eran mucho más lesivas que el onanismo, o producían mayor desgaste energético. De este modo, Llauradó pretendía, enarbolando la bandera de la equidad y la ciencia, defender la seguridad para la salud del autoerotismo reafirmando que éste no afectaba a la inteligencia, la memoria, la comprensión o toda una serie de desarreglos fisiológicos, como lo demostrarían una larga serie de intelectuales, supuestos practicantes de este hábito —Diógenes, Goethe, Gógol, Rousseau, etc.—. La aportación ácrata al estudio etiológico de la masturbación se sustentaba en señalar que la permanencia de la moral tradicional, con la defensa de la abstención sexual y la represión del erotismo, era más lesiva para el organismo que cualquier otra práctica. En su opinión, su origen se encontraba en la publicación de un panfleto de época victoria titulado "Onania" que vertía sin fundamento científico toda una serie de tópicos que, además de resultar totalmente desactualizados respecto a los descubrimientos de la época, no tenían rigor científico como para tenerlos en cuenta ${ }^{31}$.

Para Llauradó no sólo el trabajo de Roberto Nóvoa Santos liberaba a la masturbación de la carga lesiva que para la conciencia y la salud muchos le achacaban, sino que venía refutada con las aportaciones de científicos como el médico socialista Max Hoddan,

30. Estudios, n'148, diciembre de 1935, pp. 20, 21.

31. Estudios, n¹48, diciembre de 1935, pp. 20-22. Para el escrito anarquista, esta represión sexual sí que era causante de todo tipo de enfermedades psicosexuales, así como del surgimiento en la sociedad burguesa de tradición cristiana de cuatro tipos diferenciados de trastornos neuróticos asociados al sexo: «el adolescente masturbador", "la niña clorótica», "el joven impotente», "la cuarentona beata» y "el viejo sátiro». Esta realidad sólo sería superable con la remoción de las estructuras estatales y la revolución social, además de con una visión más tolerante de la sexualidad que está en la línea con la defensa de la autosatisfacción sexual del individuo siempre que sintiera necesidad de ello. De este modo, y en la línea con la retórica ácrata de la época, se intentaba tamizar la moral anarquista como la más cercana a los postulados de la ciencia, mezclando intereses y confundiendo en las vías para la solución de los problemas sociales. Estudios, $\mathrm{n}^{\circ} 134$, octubre de 1934, pp. 15-17; Iniciales, n6, junio de 1935, pp. 9-12. 
el psicólogo Wilhelm Stekel, o los sexólogos Magnus Hirschfeld y Havelock Ellis. La contribución de autores anarquistas al texto, sin embargo, iba a ser mínima dada la obsesión ácrata por la exaltación de la ciencia y la medicina como verdades supremas incontestables que están por encima de la ideología política. De este modo, sólo iba a ser citado el famoso escritor anarcoindividualista francés defensor del poliamor, Émile Armand, para la defensa del carácter animal de dichas prácticas, cuya presencia se daba también en el mundo animal. En definitiva, y siempre desde una práctica libre y equilibrada, la enfermedad se encontraría en los extremos, el egoísmo y la compulsión, pero nunca en el sexo, considerado por el autor un bien sagrado que la naturaleza ha otorgado al hombre y, por tanto, libre de pecado y moralización ${ }^{32}$ :

Podríamos continuar copiando documentación y aportar algo de nuestra cosecha, pero lo expuesto es suficiente para llevar tranquilidad a ese enjambre de masturbadores agobiados por las mil depresiones de moralistas y seudohigienistas empeñados en suprimir un acto insuprimible [...] La masturbación ni es «vicio, ni enfermedad», ni acto vergonzoso, ni nada: es el «acto indiferente» que, practicado con oportunidad y prudencia, sólo bien puede producir. Él es limpio, higiénico, intrascendente, económico, sin complicaciones ni peligros y moral, perfectamente moral, muchísimo más moral que comprar la colaboración en el burdel, en la mentira o en el matrimonio a fuerza de pesetas, de peligros, decepciones y claudicaciones $[\ldots]^{33}$.

\section{CONCLUSIONES}

La aspiración ácrata a la revolución social y a la instauración del comunismo libertario es una pieza más de un complejo engranaje político, cultural, social y mental en el que el pensamiento y la praxis del mismo son consustancialmente tan importantes como la reivindicación sindical o la lucha social. El anarquismo se fundamenta en la convicción de que una sociedad nueva debía construirse por individuos mentalmente emancipados. En este proceso de construcción de la nueva moral, en los círculos libertarios españoles, la sexualidad alcanzó una importancia capital al erigirse en arma arrojadiza contra la moral tradicional y burguesa. La vivencia de una sexualidad libre, sana y sin prejuicios se entiende, no sólo esencial para la construcción teórica de un modelo realista y alternativo de sociedad, sino una forma de diferenciarse y luchar contra el pensamiento conservador de la Iglesia o la burguesía gobernante.

Sin embargo, el acercamiento a una sexualidad más centrada en el cuerpo, la higiene, la medicalización del sexo o la etiología de las enfermedades, en definitiva, aplicar lo que Félix Martí Ibáñez resume con la frase: «[...] quedará demostrado una

32. Estudios, n'148, diciembre de 1935, pp. 21, 22.

33. Estudios, $\mathrm{n}^{\circ} 148$, diciembre de 1935, p. 22. 
vez más que en las enfermedades sexuales de los hombres, como en las enfermedades políticas de los pueblos, el mejor tratamiento es la santa Libertad»34, acabó por establecer una nueva ortodoxia. Y es, precisamente, esa libertad a la que se refiere Ibáñez a la que se intenta acoger Llauradó al defender la práctica de la masturbación. Sin embargo, el acercamiento a lo sexual en el mundo ácrata, al insertarse dentro de las corrientes médicas de la época —ligadas a intelectuales y profesionales como Havelock Ellis, Sigmund Freud, Magnus Hirschfeld o Gregorio Marañón-, antepone los estudios científicos a una visión ideologizada. De este modo, aunque la sexualidad es codificada como un mecanismo para la eliminación del autoritarismo intrínseco al orden establecido y a la moral sexual tradicional, en el fondo, se acaba estableciendo un nuevo paradigma que no permite dudar de él.

Esta «elite» cultural ácrata, conocida por sus continuas intervenciones en prensa, libros, mítines o conferencias, no acabó de liberarse totalmente del peso de la tradición. La pervivencia de cuestiones relacionadas con la moral, como las ideas de degeneración o vicio achacadas a dicha práctica, son un ejemplo de la dificultad de separar ciencia de moral. En este sentido, Llauradó se muestra como el más equidistante de los propagandistas al defender que la patologización de la masturbación se encontraba en un exceso o mala praxis, y no en un uso normal. Él, defensor del individualismo como esencia de la anarquía y convencido como cualquier anarquista de la época en el poder de la naturaleza como generadora de leyes universales superiores, defiende, a partir de la exposición de su pensamiento y de la cita de numerosos científicos y profesionales, que en la vivencia del sexo debería incluirse la libre experimentación de lo que considera es una tendencia fisiológica y natural. En definitiva, el anarquismo español de los años treinta demostró una enorme permeabilidad de ideas médicas y científicas acerca de la sexualidad, pero sin acabar de liberarse totalmente de prejuicios tradicionales de corte moral; de ahí que, como sucedía con la masturbación o la homosexualidad, estas eran consideradas manifestaciones degeneradas y propias de comportamientos sexuales alterados.

34. Estudios, no 143 , julio de 1935, p. 16. 